\title{
Automation of the one-storey underground parking space organization
}

\author{
Natalia Knyazeva $^{1^{*}}$ and Anastasia Kolosova ${ }^{1}$ \\ ${ }^{1}$ Moscow State University of Civil Engineering (National Research University), 129337, \\ Yaroslavskoye shosse, 26, Moscow, Russia
}

\begin{abstract}
With the growing car population in big cities, the problem of its keeping in conditions of a compact urban area has happened. The organisation of parking space in a different way has resolved this issue. Underground parking was in demand in many countries even in the XX century. By the way, they are becoming more and more popular now. The design of car parking is based on legal documents, which regulate the size of car parking seats and the width of the passage inside the garage. It is expedient to use evolutionary algorithms as one of the tools of algorithmic modelling for automation of design the car parking lots and for identifying the most effective and profitable way of the car parking space planning. So, the process of looking for the most optimal solution in underground car parking designing.
\end{abstract}

\section{Introduction}

The amount of cars in the streets, especially in the megalopolises, has increased dramatically for twenty years. So, the parking space in the residential blocks demand became higher. The best and the most effective way to solve this problem is the building of underground car parking lots. The underground car parks allow reducing the land much more economically as they can be located under roads and different buildings. Besides, the benefits of underground parking include the improvement of energy because of the temperature constancy. Every season of the year the temperature underground can be from eight to thirteen degrees centigrade. Also in parking lots exhaust emissions in the air are going through the air vent. It hurts the environment less than in the case of open car parks.

\section{The evolution of underground parkings in the world}

The history of underground parking starts in Spain. The first underground parking was built in Barcelona in 1910, and the first two-level underground parking lot appeared under the buildings of California State University in 1964 [1]. Automatic or mechanized parking lots have been invented by Chinese and Korean engineers. Multilevel mechanized car parks can be both open and underground.

\footnotetext{
* Corresponding author: nknyazeva@mgsu.ru
} 
There is a robotic parking lot under Cube Business Center in England. It is located about twenty meters below the ground. The elevators implement the process of a car rising and setting, and the robotic platforms make move a vehicle in horizontal directions to the needed parking place. By the way, it is necessary only to press the special button on the "key", which was given to the owner of the car, to put the vehicle in the parking lot or to take it away.

There is also an example of the construction of robotic underground parking in Russia. A couple of underground car parks is situated in Quattro Corti Business Center, which is located in Saint Petersburg. These parking lots are for 128 parking spaces together. The underground car parks were open for use in 2010. To tell the truth, the project was developed by Italian architects and engineers, and it is based on the Interpark technique [1].

The programme of the development of two-eight-level underground parking construction has been worked out in the capital of France. The first turn of the programme includes about fifty-eight thousand parking spaces, which overall area is 1,5 million $\mathrm{m} 2$. There are four-six-level car parks under the domestic territories and there are parking lots in two-four levels under the seven-ten floor buildings. Similar programs are led in other countries too. For example, in the area surrounding Moscow's VDNKh subway station, the eight-level underground parking was open in 1988. It could receive two thousand and a hundred cars. Besides, parking lots in the Leninsky, Leningradsky and Prospekt Mira, next to the Victory Park on Poklonnaya Gora, near Moscow-City and in the other parts of the capital of Russia were open to using.

Because of the popular Sydney Opera House opening, there has been a problem with a shortage of parking spaces in Australia. They had to solve that immediately. So, it was decided to build twelve-level underground parking that included one thousand and a hundred parking spaces. The thirty-two meters high construction is located twenty-eight meters below the ground. It is shaped in the form of a torus, its internal diameter is thirtysix meters, and the external one is seventy-two meters long.

\section{Standards of the design of car parking}

According to the text edition to standard SP 113.13330.2016 "Parkings" [2] about the storage of vehicles, there are some different types of car parks. They are "arena" parking, which has the number of parking spaces in the one open area, "car boxes" which are isolated from each other, combined and cell-type parking lots. The most economical way of parking space organization is "arena" parking. Be the way, the "car boxes" parking is the most preferable type of car storage in potential owner's opinion.

The parking area includes parking spaces and passage inside the garage. While the design of parking area people should take into account vehicle size and its minimum turning radius [2].

The standard size of parking spaces is controlled by standard SP 113.13330.2016 "Parkings" [3]. The size of parking space accepts adjusted for minimum allowed safety clearances according to the class (type) of the car. So, it is needed to have an area, which size is $2795 \times 5860 \mathrm{~mm}$, for a "large" class car, which size is $1995 \times 5160 \mathrm{~mm}$ [3].

The minimum allowed width of passage inside the garage depends on the car placement scheme and class (type) of vehicle. By the way, on the parking, where it is planned to keep "large" class cars in "arena" placement with the installation of vehicles in front at right angles to the driving axis, the width of passage inside the garage should not be less than $6100 \mathrm{~mm}$.

Besides, each parking lot has to be fit for fire safety. It is one of the main requirements for projects according to standard GOST 12.1.004 [4]. It is necessary to organize escape routes from the parking place for both vehicles and pedestrians. Also, it is important to use 
fire-resistant materials in construction. These materials should match the firefighting system. If the parking is mechanized, it should be equipped with automatic fire-fighting appliances according to SP 5.13130 standard [5].

\section{The tools of the algorithmic modelling}

The design of underground parking is a labour-intensive task, especially if it has an intricate shape. The expert has to make a plan of the placement of the maximum possible number of parking spaces adjusted all design norms. It is not advisable to calculate all possible variants of a large parking layout manually. We can automate this task using the tools of algorithmic modelling, the evolutionary algorithms indeed [6].

An evolutionary algorithm is the branch of artificial intelligence theory, which models the processes of natural selection. The idea that all living organisms evaluate with time and evolved from a common ancestor belongs to Charles Darwin. He explained the evolution theory in his book "On the Origin of Species" which was published in 1859. Over time, it won widespread currency in the world and in construction indeed [7].

Evolutionary computing was firstly mentioned in the sixties of the twentieth century. To the eighties, evolutionary computing has already come into common use but can be applied in works only by programmers. Scientists like I. N. Serpik, N. Salingaros, A. G. Yuryev and E. Hayman learned the ability to adapt evolutional and genetic algorithms for architecture and optimization of structural design. With the development of algorithmic modelling and visual programming, the architectures and designers were able to find the optimal solution in many different tasks using the evolutionary algorithms [7]. The most commonly used ones are the additional plug-ins to the visual programming editing programs like Dynamo and Grasshopper. For example, plug-in Galapagos, included in Grasshopper, or Wallacei that requires an extra installation [8].

The operating principle of evolutionary silvers is easy. The work is based on the exception of the worst genes (variables with the lowest value) and the increase of the number of the best genes (variables with the highest value). Plug-in Galapagos is an easier and more obvious thing for using than Wallacei. Plug-in Wallacei has extended functionality, statistics and the ability to visualize simulation results. One of the basic advantages of Wallacei evolutionary solver over Galapagos is the ability to connect more than one editable variable and some different objective functions. Wallacei also has a large analytics unit Wallacei Analytics. There is an opportunity to take out the separate generation with its parameter.

\section{The practical application of the evolutionary algorithm}

\subsection{The foreign experience}

In Australia, the Salzburg Biennale, an annual classical music and performing art festival, took place in White Noise pavilion in 2011. That pavilion has been created by Soma Architecture. The project was a winner of the two-step competition, which was happened in October of 2010. The pavilion is a complex set of many repetitive elements, while it looks like a whole from a distance. The pavilion's self-supporting shell consists of six-meters aluminium profiles. The designers developed a rule, which was describing the geometry of the pavilion model. They also set the limits of design varieties for the satisfaction of the intended aesthetic features of the building. The possible positions for aluminium profiles were generated by an evolutionary algorithm, and then the special plug-in, that could compute loads, analysed the positions. The algorithm excepted failed shell versions and 
modified the successful ones. As a result, the most effective position of aluminium profiles has been found. It was a shape of the shell with the fewest number of elements and their connections [10].

\subsection{The design of car parking area with tools of the algorithmic modelling}

It is advisable to use a tool of evolutionary algorithms Wallacei in the design of underground parking for detecting the most effective option of using the parking area. It helps to reduce time and labour in the decision-making process.

The objective is based on looking for a location of parking spaces, in which the number of parking places will be maximum. The installation of vehicles at right angles to walls is considered the most effective in terms of waste of parking territory. It is rational to place cars along the external parking walls and to erect secondary walls on the remaining area. We should collocate parking spots along the middle walls.

One of the sub-tasks is finding an external wall of the parking structure, parallel to which secondary walls should be installed in the middle of the parking lot. In Grasshopper modifiable parameters are set through the "Number Slider" node. The user of this created instrument of the automation of underground parking organization can rename node "Number Slider", which is needed for looking over the external walls, in "Outside Parking Faces" to make the work more comfortable. The modifiable parameters are connected with Wallacei through the gate "Genes", and the objective functions are connected to Wallacei through "Objectives". So, the first objective function that needed to be connected to Wallacei, is the function for determination of the number of parking spaces located in the useful parking area.

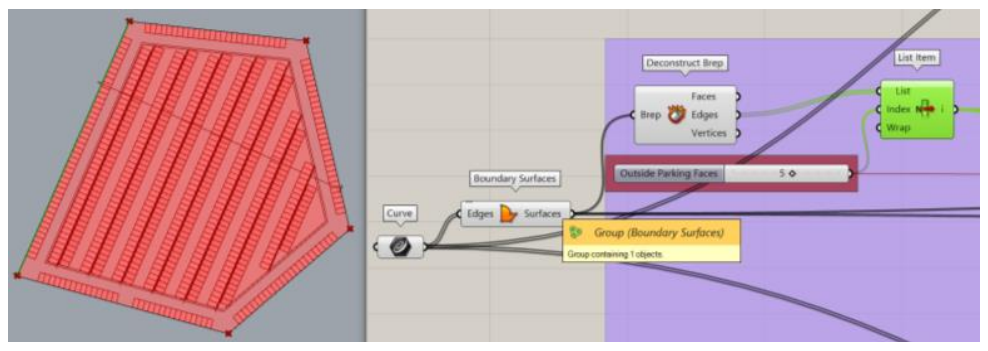

Fig. 1. Determination of the curve, parallel to which secondary walls should be placed.

Then, for erecting secondary walls, we can draw a perpendicular to the selected line, an external wall of the parking. After that, it is needed to divide the perpendicular with lines at regular intervals of a certain length, which depends on the normed parking space length, necessary width of passage and the thickness of the secondary walls. The dropped perpendicular should be as long, as possible. So, it is the second objective function connected to Wallacei. The determination of the point from which the perpendicular should be dropped is implemented through the node "Number Slider". This node is the second modifiable parameter connected to Wallacei solver through "Genes". 


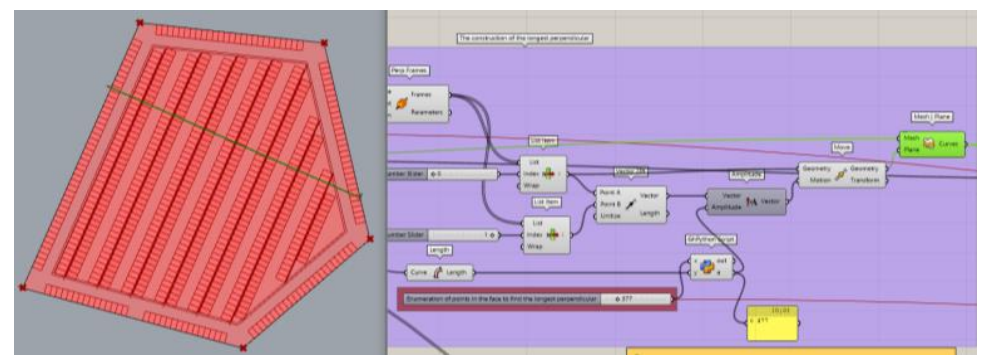

Fig. 2. Determination of the perpendicular.

There is another way of drawing a line that is perpendicular to the needed secondary walls. So you should draw a circle around the parking lot. This circle's radius equals the distance between the centre of the parking lot's shape and the corner of the shape which is the farthest from it. After that, it is necessary to find out through which end of the chosen external wall's segment we have to draw the line perpendicular to the wall. The process of going through all the options is implemented through the node "Number Slider". This node is a modifiable parameter connected to Wallacei solver through "Genes".

An extra problem was the placement of parking spaces in the corners of the parking structure. It was necessary to provide comfortable entry and exit of vehicles from the parking spots. The circles with their centres at the intersections of external walls of the parking lot were drawn for that purpose. Radiuses of the circles depend on the angle between a couple of external walls and the length of a chord. The chord is the line laid between extreme parking spaces, which are placed along a couple of external walls. The chord's length equals 2.5 times the length of the parking space. In this way, I coped to delete parking spots located in the area of constructed circles.

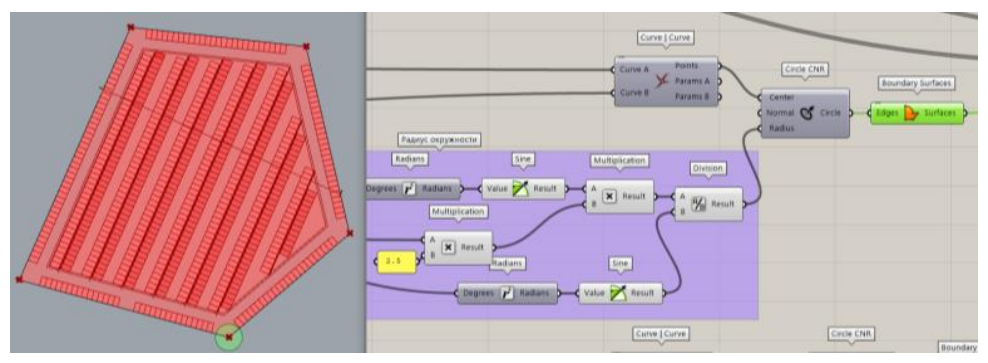

Fig. 3. Construction of the circles in the corners of the parking lot.

Fool algorithms of the parking lot's automatic design are presented in the following flowcharts: 


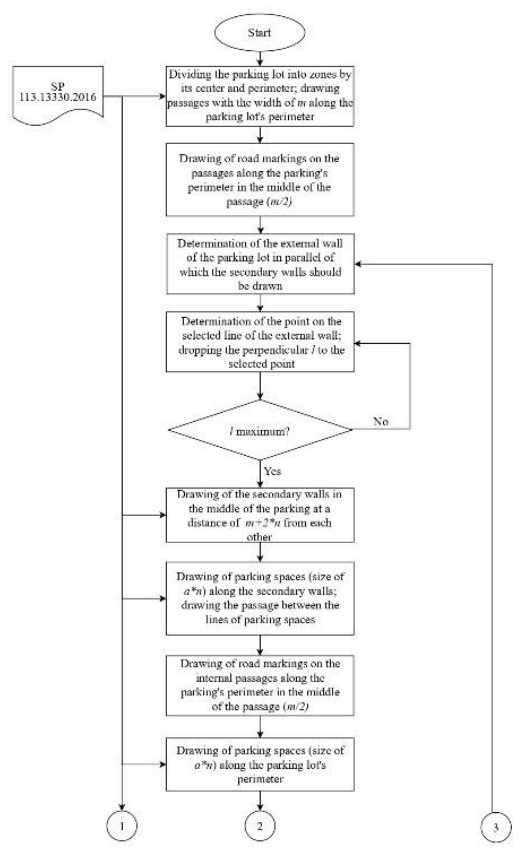

Fig. 4. The flowchart of the parking lot's automatic design (with the help of perpendicular) 1 .

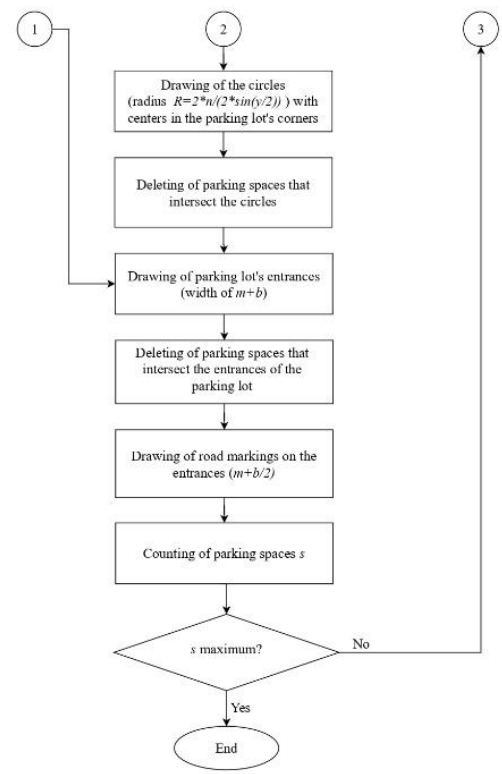

Fig. 5 The flowchart of the parking lot's automatic design (with the help of perpendicular) 2 . 


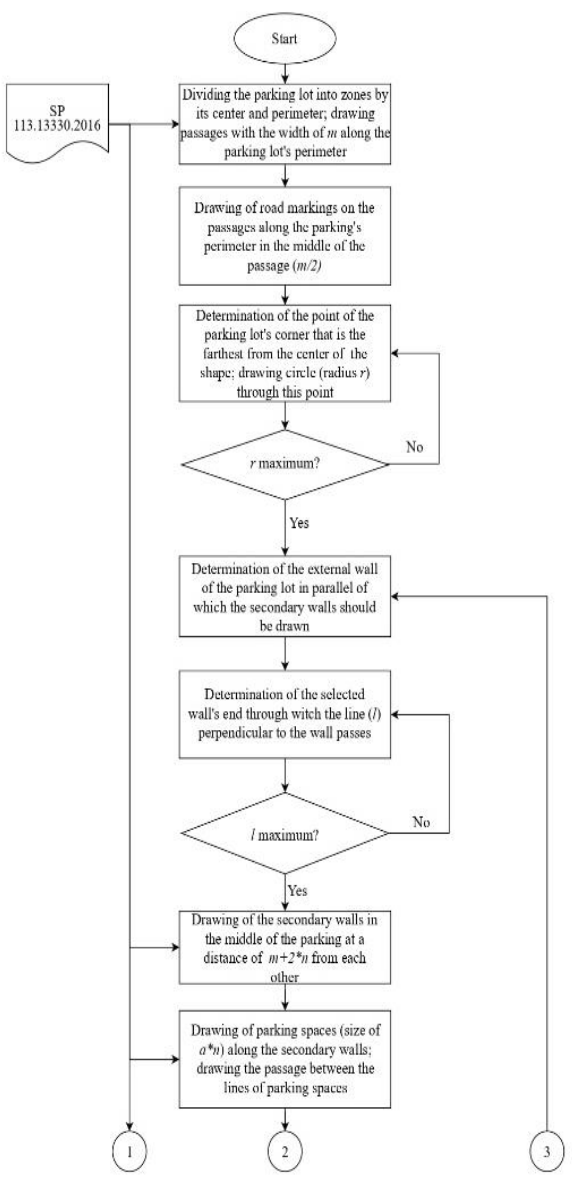

Fig. 6. The flowchart of the parking lot's automatic design (with the help of circle) 1 . 


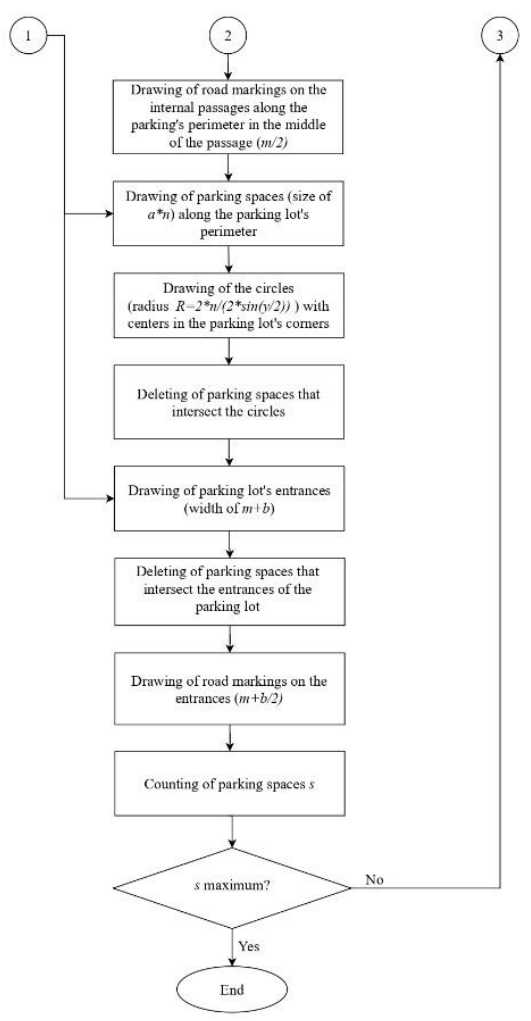

Fig. 7. The flowchart of the parking lot's automatic design (with the help of circle) 2 .

Created instrument of automation design of underground parking allows making layout decisions in a room with various geometries if its number of external edges is within three and ten.

Evolutionary algorithms won widespread currency in different spheres, in construction indeed. Their usage in algorithmic modelling allows making decisions quickly and effectively not only to programmers but also to the designers.

\section{References}

1. S. Ison, L. Budd, International Encyclopedia of Transportation, 113-117 (2021)

2. N.Milosavljevic, J.Simicevic, Sustainable Parking Management, Practices, Policies, and Metrics, 41-69 (2019)

3. I.Duvanova, T.Simankina. A.Shevchenko, T.Musorina, A.Yufereva, Procedia Engineering 165, 1784-1793 (2016)

4. M.A. Dulebenets, International Encyclopedia of Transportation, 2392-400 (2021)

5. Zh.Li, L.Miao, Automation in Construction, 119, 103377 (2020)

6. A.Fahim, M.Hasan, A.Chowdhury, Helion 7, 5, e07050 (2021)

7. A.M.Said, A.E.Kamal, H.Afifi, Computer Communications, 172, 10-18 (2021)

8. X.Hu, J.Bao, T.Ma, Transportation Research Interdisciplinary Perspectives, 9, 100311 (2021) 